\title{
As paixões aristotélicas na caracterização de dois universos: a língua inglesa na escola de idiomas e na escola de ensino regular
}

\author{
Maria Flávia Figueiredo \\ Universidade de Franca \\ mariaflaviafigueiredo@yahoo.com.br
}

Sinelle Duarte

PG-Universidade de Franca sduarte1986@yahoo.com.br

\begin{abstract}
Resumo
Aristóteles, instigado pelo entendimento das reações humanas diante dos diferentes discursos, advoga que as paixões são sentimentos que alteram as pessoas de tal modo que as fazem modificar seus julgamentos. Paixões são suscitadas em toda interação comunicativa, inclusive no processo ensinoaprendizagem. Sendo assim, este estudo pretende analisar as paixões despertadas em aprendizes da língua inglesa oriundos de duas realidades de ensino: a escola de ensino regular pública e a escola de idiomas, de caráter privado. Procedemos, inicialmente, a um estudo de campo para a coleta de dados. Com base nela selecionamos as amostras a serem analisadas com vistas ao confronto dos dois grupos de participantes selecionados. Tomando como instrumento de pesquisa a redação escolar, o corpus da pesquisa constituiu-se de dez redações elaboradas pelos aprendizes do idioma acerca do tema "O inglês na minha vida". Esses textos foram analisados à luz da teoria das paixões proposta por Aristóteles. A investigação se deu por meio de uma análise qualitativa dos dados. Os resultados da pesquisa confirmaram nossa hipótese de que as situações de ensino-aprendizagem distintas também suscitam paixões variadas em seus aprendizes e nos permitiu uma reflexão sobre as estratégias metodológicas de abordagem do conteúdo e a inserção do aprendiz na língua alvo em diferentes realidades de aprendizado.
\end{abstract}

Palavras-chave: processo ensino-aprendizagem; língua inglesa; paixões. 


\section{Abstract}

Aristotle, instigated by the understanding of human reactions to different discourses, advocates that passions are feelings that affect people in such a way that make them modify their judgments. Passions arise from every communicative interaction, including the teaching-learning process. Therefore, this study intends to analyze the passions aroused in English language learners from two teaching realities: the public regular school and the private language school. We initially conducted a field study for data collection. From there, we selected the samples to be analyzed aiming at the comparison of the two selected groups of participants. Having academic compositions as a research instrument, the corpus of the research consists of ten essays compiled by the language learners on the theme "English in my life". These texts were analyzed in light of the theory of the passions proposed by Aristotle. The research was carried out through a qualitative analysis of the data. The results confirmed our hypothesis that the different teaching-learning situations also raise varied passions in the learners and allowed us to reflect upon the methodological strategies to approach content and the insertion of the learner in the target language in different learning realities.

Keywords: teaching-learning process; English language; passions.

\section{Introdução}

No decorrer de qualquer processo de ensino-aprendizagem são inúmeras as emoções experimentadas pelos aprendizes em relação a tudo o que constitui o objeto de seus estudos, e esses sentimentos que acometem os discentes podem mantê-los em conjunção com o aprendizado, estimulando-os, assim como podem atuar de modo contrário, afastando-os.

Voltando nossas atenções para o ensino-aprendizagem de uma língua estrangeira, essas emoções não são percebidas apenas no contexto de aprendizagem que ocorre na sala de aula. A relação que os estudantes mantêm com a língua estrangeira ultrapassa os limites do ambiente escolar e, consequentemente, seus sentimentos em relação à língua e ao seu aprendizado também acompanham essa variação.

Atuando como docente de língua inglesa em uma escola de idiomas e em uma escola de ensino regular pública, a forma de recepção do idioma pelos alunos de ambas as instituições assim como as emoções vivenciadas por cada um desses grupos de estudantes no 
que concerne ao aprendizado da língua sempre foram questões que me instigaram devido ao fato de essas duas realidades de aprendizado serem estereotipadas como opostas. A primeira instituição é caracterizada como o ambiente propício para a aquisição de uma língua estrangeira, enquanto a segunda tem seu ensino desvalorizado como consequência de vários fatores que distinguem essas duas realidades, a começar pelo público ao qual atendem e as condições de aprendizado oferecidas a esse público, fatores estes que privilegiam a instituição privada.

A teoria aristotélica das paixões, que trata dos sentimentos despertados no sujeito e fazem variar seu julgamento, encaminha-nos para a percepção de que as paixões suscitadas na interação de aprendizagem da língua inglesa afetam os sujeitos envolvidos nesse processo. As variações nos julgamentos dos sujeitos levam-nos a alterar suas concepções em relação ao idioma, o que, por conseguinte, reflete em suas atitudes, aproximando-os ou distanciando-os do objeto de estudo. À vista disso, objetiva-se neste estudo verificar quais paixões são despertadas nos aprendizes da língua inglesa em uma escola de idiomas e em uma escola de ensino regular.

Diante das divergências entre essas duas instituições de ensino, levantamos a hipótese de que as paixões afloradas nos estudantes de língua inglesa de uma escola de idiomas e de uma escola de ensino regular distinguir-se-iam por se tratar de realidades díspares de aprendizado. Além disso, consideramos também a hipótese de que essas paixões, que divergem de um ambiente para outro, poderiam interferir na identificação do aluno com a língua estrangeira.

Além de Aristóteles (2003; 2007; 2009), que apresenta a teoria das paixões, o arcabouço teórico desta pesquisa é também composto por Meyer (2007), que amplia a concepção a respeito da influência que as paixões exercem sobre o auditório; Hume (2001) e Maturana (1998), que discutem a dicotomia paixão e razão; Lightbown e Spada (2006), que abordam alguns fatores que afetam o aprendizado de uma língua estrangeira; Coracini (2007), que traz reflexões acerca do sujeito na aprendizagem de uma segunda língua; e Laplanche e Pontalis (2001) e Zimerman (2001), que ampliam o conceito de afeto segundo a visão da psicanálise.

Apesar de não terem feito parte da base teórica deste estudo, devemos ressaltar que há também autores brasileiros que tratam da 
dimensão afetiva no ensino/aprendizagem de línguas, é o caso de Mastrella-de-Andrade (2011) e Aragão (2008).

O corpus para este estudo constitui-se de dez redações redigidas por estudantes da língua inglesa, sendo cinco textos provenientes de uma escola de idiomas e os outros cinco oriundos de uma escola de ensino regular. Os alunos das duas instituições de ensino apresentam idades equivalentes, que variam entre 10 e 15 anos, e as redações tiveram como tema: "O inglês na minha vida".

A redação é um relato que nos permite perceber quais as paixões suscitadas na interação de aprendizagem da língua estrangeira, no entanto não tratamos neste trabalho da relação professor-aluno, pois não analisamos o processo em que as paixões foram despertadas e, sim, com base no relato do aprendiz podemos apreender as paixões verificáveis em seus textos. A análise possibilita-nos enxergar a relação do estudante de língua estrangeira com a língua alvo de seus estudos.

Para a execução desta pesquisa foi realizado primeiramente um levantamento bibliográfico acerca das paixões aristotélicas. $\mathrm{Na}$ sequência ocorreu a seleção dos grupos de participantes a serem investigados para que se procedesse a um estudo de campo para a coleta de dados, que se deu por meio da investigação escolar. Em seguida foi possível a seleção das amostras a serem analisadas de modo que pudéssemos confrontar os dois grupos de participantes selecionados: estudantes que frequentam um curso de idiomas e alunos que têm acesso ao ensino da língua somente no ambiente escolar, na educação regular. Assim, ocorreu a configuração do corpus. De posse dessas amostras, procedeu-se à análise qualitativa do corpus.

Cada um dos grupos de participantes foi dividido em quatro estratos, de acordo com o grau de escolaridade dos estudantes, agrupando assim os aprendizes das duas instituições de ensino em alunos pertencentes aos $6^{\circ}, 7^{\circ}, 8^{\circ}$ e $9^{-}$anos. A investigação das paixões será realizada pela análise de cinco amostras de cada um dos grupos de participantes.

O primeiro grupo de participantes, que apresenta as redações dos alunos que mantêm o contato formal com a língua inglesa apenas na escola de ensino regular, apresenta cada um de seus estratos constituído da seguinte forma: 36 alunos estão no $6^{\circ}$ ano, 17 alunos no $7^{\circ}$ ano, 13 alunos no $8^{\circ}$ ano e 15 alunos no $9^{\circ}$ ano. Tendo em vista que 
"a composição da amostra deve manter a mesma proporção dos estratos” (DUARTE; SOARES; RODRIGUES, 2011, p. 8), selecionamos aleatoriamente duas amostras do $6^{-}$ano e uma amostra dos demais anos, totalizando as cinco amostras pretendidas, uma vez que a porcentagem de alunos do estrato do $6^{\circ}$ ano constitui mais do dobro dos demais estratos.

Seguindo o mesmo procedimento efetuado na seleção das amostras do primeiro grupo de participantes, agrupamos os alunos da escola de idiomas com idades equivalentes aos da escola de ensino regular de forma que fosse constituído esse segundo grupo. Em seguida, separamos esse grupo também em quatro estratos de acordo com o ano no qual esses alunos estão matriculados na escola de ensino regular. Do mesmo modo como fizemos com o primeiro grupo, elegemos, também de forma aleatória, duas amostras do $6^{-}$ano, uma amostra do $7^{\underline{0}}$ ano, uma amostra do $8^{\underline{0}}$ ano e uma amostra do $9^{\underline{0}}$ ano.

De posse dessas dez amostras, deseja-se, portanto, confrontar os dois contextos de ensino: o ensino da língua inglesa em uma escola de ensino regular e seu ensino em uma escola de idiomas. Essa comparação dar-se-á pela análise dos textos redigidos pelos adolescentes dessas duas escolas de forma que sejam observadas as paixões reveladas em seus textos.

Por envolver seres humanos, esta pesquisa foi submetida ao cauteloso escrutínio do Comitê de Ética e Pesquisa (Cepe), sediado na Unifran. Dessa forma, conforme solicitação desse órgão, todos os dados da pesquisa foram devidamente registrados na Plataforma Brasil, sob o protocolo número 05934212.7.0000.5495.

Este estudo pretende contribuir com o trabalho docente, facilitando a atividade do professor de língua estrangeira na inserção do aprendiz na língua alvo. Conhecendo o público com o qual está lidando por meio das paixões que caracterizam cada grupo específico de estudantes, a tarefa do professor de proporcionar a identificação do aluno com a língua é facilitada, uma vez que pode preparar-se antecipadamente para as realidades distintas de aprendizado com as quais deverá interagir. No entanto, é necessário ressaltar que os dados que caracterizam cada um dos grupos específicos de estudantes podem sofrer alterações de acordo com a variação de escolas, professores, localidade, entre muitos outros fatores que podem vir a influenciar para que esse resultado não seja coerente com outros contextos. 
Procuramos neste trabalho, em um primeiro momento, elencar as paixões aristotélicas e ressaltar sua função no ato retórico, inclusive quando comparadas à razão.

Em seguida, apresentamos algumas análises realizadas bem como seus resultados e as implicações da pesquisa no ensinoaprendizagem de uma língua estrangeira.

\section{As paixões na busca da identificação}

Esta primeira seção do trabalho é destinada à apresentação das paixões propostas por Aristóteles assim como a evidenciar a função desses sentimentos no ato comunicativo, explicitando o modo pelo qual elas podem conduzir os interactantes à identificação.

Considerando que qualquer discurso é constituído por perguntas e respostas, Meyer (2003, p. XL) conceitua o termo paixão como uma "resposta ao outro". Assim, cabe ao orador conduzir o seu discurso de modo que as paixões que ele possa despertar em seu auditório resultem em respostas que venham ao encontro do que pretendia ouvir.

A paixão é um artifício que o orador dispõe para persuadir seu público a aderir à sua causa, pois a paixão é "um poderoso reservatório para mobilizar o auditório em favor de uma tese" (MEYER, 2007, p. $38)$.

Aristóteles (2009, p. 254), em Ética a Nicômaco, defende que "nós somos, espontaneamente, a situação em que nos encontramos, afetados desta ou daquela maneira. Os fenômenos sofrimento e prazer são, assim, indicações da nossa maneira de ser e estar, isto é, do modo como cada situação nos dispõe". Dessa maneira, uma mesma paixão pode ser considerada positiva ou negativa, dependendo da situação em que ela for despertada e de acordo com o sujeito que for tomado por ela.

Quando Aristóteles afirma que, independentemente da situação comunicativa, somos afetados de algum modo, depreendemos que afetos estão envolvidos em qualquer interação. Consoante Zimerman (2001, p. 23), "a etimologia da palavra afeto evidencia que ela alude a sentimentos que afetam - tanto no sentido de afeições como de 
afecções - o psiquismo do sujeito". Dessa forma entendemos que o afeto acarreta mudanças psicológicas no sujeito afetado.

Somando-se a essa visão de afeto proposta por Zimerman, que o relaciona com o psiquismo humano, Laplanche e Pontalis (2001, p. 9) advogam que o afeto é "um termo que a psicanálise foi buscar na terminologia psicológica alemã e que exprime qualquer estado afetivo, penoso ou desagradável, vago ou qualificado", ou seja, o afeto altera o ser humano provocando-lhe sensações diversas.

Recorremos também ao dicionário Houaiss (2001) para verificar as concepções apresentadas para o termo "afetivo" e encontramos: vocábulo "relativo aos afetos, aos sentimentos". Assim, fomos buscar a definição da palavra "afeto" e observamos que, segundo a psicologia, "afeto" é um "sentimento ou emoção em diferentes graus de complexidade, por exemplo, amizade, amor, ira, paixão, etc.", ou ainda, "estado, limitado no tempo, provocado por estímulos externos ou por representações, acompanhado de certo grau de tensão e composto de sentimentos particulares" (HOUAISS, 2001).

Sabendo que as paixões, segundo Aristóteles (2003, p. 5), "são todos aqueles sentimentos que, causando mudança nas pessoas, fazem variar seus julgamentos, e são seguidos de tristeza e prazer", podemos relacionar o afeto às paixões. No momento em que, na definição de afeto, se menciona que ele é acompanhado por certo grau de tensão, podemos entender essa tensão como a mudança que as paixões, quando suscitadas, provocam nas pessoas. A seguir, expomos as 14 paixões aristotélicas e, para cada uma delas, atribuímos uma definição de forma bem sintética embasada nos conceitos de Aristóteles (2003) em Retórica das paixões.

a) Cólera: atua como meio de vingança por um dos interlocutores que se sente injustiçado.

b) Calma: surge em oposição à cólera, eliminando as diferenças entre os interactantes.

c) Temor: ocorre quando consideramos que algum dano ou mal possa vir a ocorrer.

d) Confiança: superioridade perante o afastamento do temível.

e) Amor: o desejo e a realização do que se julga bom, não para si, mas para o outro. 
f) Ódio: mais avassalador que a cólera, deseja provocar algum dano e é incurável.

g) Vergonha: na projeção que faço da imagem do outro como superior, torno-me inferior.

h) Impudência: contrária à vergonha, a imagem do outro não carece de importância.

i) Favor: serviço prestado ao outro sem obter nenhuma vantagem pessoal.

j) Compaixão: pesar por algum mal que atinge quem não o merece.

k) Indignação: pesar por sucessos que ostenta quem não o merece.

1) Inveja: pesar por sucessos de pessoas iguais a nós no desejo de privá-las desse benefício.

m) Emulação: desejo de igualar-se ao outro a quem consideramos semelhantes a nós.

n) Desprezo: contrário à emulação, sentimento perante o que não atribuímos valor algum.

Considerando-se o conceito de paixão como resposta ao outro, Meyer (2003, p. XLVII) advoga que as paixões "visam a definir a identidade do sujeito relativamente a outrem", dessa forma, é nessa resposta ao outro que cada um vai construindo sua identidade. As paixões, conforme a interação na qual elas são despertadas, ou recriam a simetria entre seus interactantes, levando-os à identificação, ou tendem para a ruptura, intensificando ainda mais a distância entre eles. "Identidade e diferença, supostas ou reais, eis o que na verdade parece governar a estrutura aristotélica das paixões" (MEYER, 2003, p. XLIX).

Finda a apresentação das paixões aristotélicas e a explanação sintetizada de sua atuação no sujeito, abordaremos, na sequência, o papel desempenhado pelas paixões no relacionamento humano, momento em que as emoções disputam com a razão tentando aflorar sentimentos em um sujeito considerado racional. 


\section{As paixões na escola regular: a construção de um perfil}

Após essa sucinta discussão a respeito das paixões afloradas na interação comunicativa, nesta seção apresentamos excertos de algumas das redações investigadas provenientes da escola de ensino regular e também caracterizamos essa instituição de ensino.

$\mathrm{Na}$ transcrição dos trechos das redações fomos fiéis aos textos redigidos pelos alunos para que nenhuma interferência camuflasse alguma informação que o texto original pudesse apresentar.

Referindo-nos, em um primeiro momento, apenas à escola de ensino regular, os estudantes de língua inglesa, ao redigirem frases como

\footnotetext{
"Eu adoro o inglês é superlegar na minha vida."

"O meu cotidiano no inglês é superinteressante."

"Eu adoro as aulas de inglês."
}

e ao fazerem uso de palavras da própria língua alvo em seus relatos, como "kisses" em vez de "beijos", além de utilizarem o desenho de corações em seus textos como uma forma concreta de demonstrar seu afeto pelo idioma, isso tudo mostra que esses aprendizes estão em conjunção com o idioma, ou seja, o amor está presente nessa interação de aprendizagem, uma vez que o amor, segundo Meyer (2003, p. XLIV), "é o próprio lugar da conjunção, da associação".

$\mathrm{O}$ amor foi a paixão predominante entre os integrantes da escola de ensino regular, tendo sido manifestada por todos os aprendizes do idioma, o que significa que estes mantêm uma relação de simetria com a língua inglesa.

Prosseguindo a análise, deparamos com as seguintes frases nos textos desses aprendizes da língua estrangeira:

"Eu não sabia fazer nada mais eu comecei a prestar atenção na aula e foi ai que eu comecei a aprender."

"E sem falar na professora que é muito inteligente."

"Pretendo aprender falar em inglês eu adoro e curto de montão ver uma pessoa falar em inglês." 
Nesses excertos, percebemos que a emulação é manifestada nesses aprendizes a partir do momento em que eles visualizam que outros já detêm um conhecimento ainda não compartilhado por eles, então tomam medidas para que eles também alcancem esse domínio da língua. No primeiro caso apresentado, o aluno decidiu prestar atenção na aula buscando alcançar esse aprendizado. Além disso, outro indício da emulação é o sujeito emulado procurar por modelos para querer igualar-se a eles. Nos segundo e terceiro excertos, os discentes expõem modelos que desejam seguir, e esses modelos são, respectivamente, a professora e falantes do idioma, na visão de Meyer (2003, p. XLVI), “a emulação quer imitá-lo".

Outra paixão que podemos evidenciar entre os discentes da escola de ensino regular é a confiança, e esse sentimento pode ser percebido quando um dos adolescentes faz a seguinte menção em seu texto:

"O inglês torna a gente mais sabios entre as letras, frases $e$ palavras."

Sabendo-se que a confiança, consoante Meyer (2003, p. XLV) "provém de uma certa superioridade tanto sobre as coisas quanto sobre as pessoas", entendemos que este aprendiz visualiza, no domínio da língua inglesa, essa superioridade.

Em uma das redações, um dos estudantes exprime seu sentimento em relação à língua estrangeira da seguinte forma:

"Eu pensava que o inglês era uma porcaria e não tinha valor nenhum."

Com essa assertiva, o aprendiz expressa que o idioma carece de importância na sua vida, e esse sentimento remete-nos ao desprezo, uma vez que "o desprezo o desvaloriza" (MEYER, 2003, p. XLVI).

Outro adolescente declara sua relação com a língua alvo de seus estudos de outra forma:

"Eu não sabia fazer nada mais eu comecei a prestar atenção na aula e foi ai que eu comecei a aprender e fui gostando das aulas." 
Percebemos que num primeiro momento esse aluno se encontrava distante da língua inglesa, sendo tomado por paixões que o afastavam ainda mais do idioma, pois seu filtro afetivo se encontrava alto. 'Um aprendiz que está tenso, ansioso ou chateado pode 'repelir' a absorção de informações, tornando a aquisição indisponível" (LIGHTBOWN; SPADA, 2006, p. 37, tradução nossa). No entanto, a partir do momento em que a tensão diminui e a calma se apodera desse adolescente, ele parece tornar-se efetivo, uma vez que "a calma é a aceitação de uma relação" (MEYER, 2003, p. XLIV). Esse estado emocional mantém o filtro afetivo do aprendiz baixo, criando assim uma situação propícia para a aquisição de uma segunda língua.

Os relatos dos estudantes de língua inglesa, por intermédio de suas redações, permitiram-nos identificar as seguintes paixões presentes nesse contexto de ensino-aprendizagem: o amor, a emulação, a confiança, o desprezo e a calma, conforme visualizamos na Figura 1.

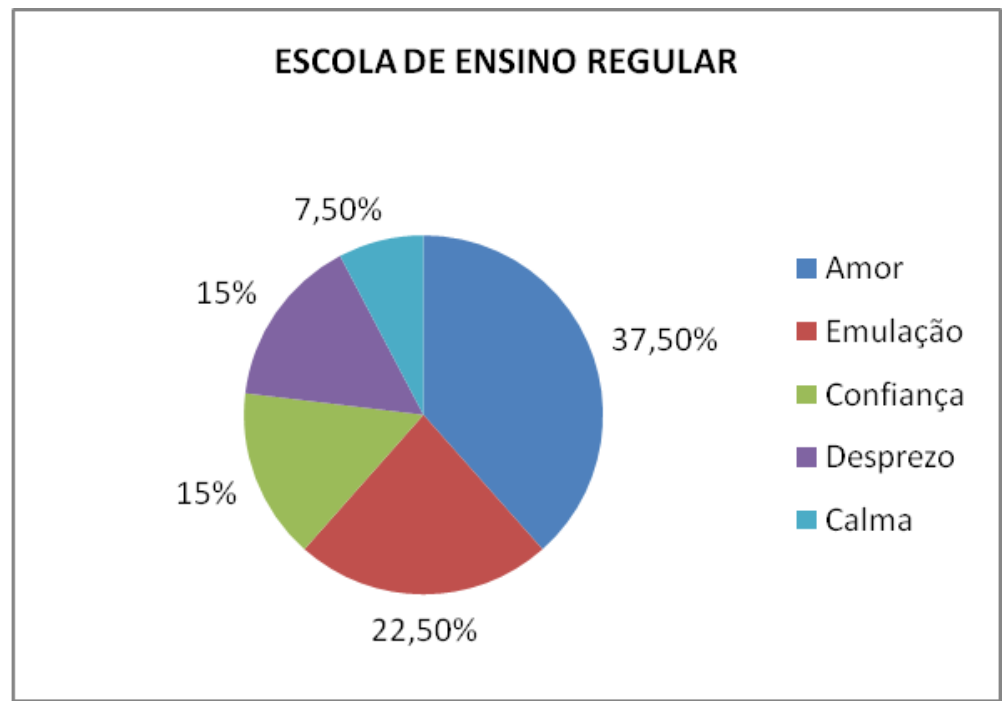

Figura 1. As paixões manifestadas em textos de alunos da escola de ensino regular

1 "A learner who is tense, anxious, or bored may 'filer out' input, making it unavailable for acquisition" (LIGHTBOWN; SPADA, 2006, p. 37). 
No entanto, as análises permitiram-nos não apenas identificar as paixões que se fazem presentes em cada realidade de aprendizado da língua inglesa, mas também nos levaram a apreender alguns aspectos específicos apresentados por cada uma das instituições de ensino que caracterizavam cada um desses ambientes de aprendizado e que contribuíam para que determinadas paixões fossem despertadas em cada escola.

Um primeiro fator que podemos destacar como exclusivo aos aprendizes da escola de ensino regular é o desconhecimento do idioma anterior à sua apresentação no ambiente escolar. Muitos desconheciam até mesmo a terminologia "inglês" até o primeiro contato que tiveram com a língua na sala de aula. Essa característica é nítida nos textos analisados, e podemos transcrever uma dessas passagens das redações para ilustrar esse desconhecimento dessa língua estrangeira pelos alunos:

“Antes eu nem sábia o que significava inglês eu só pensava em português mais com o passar dos dias fui começando a estudar inglês."

Nesse trecho o discente expressa que seu primeiro contato com a língua inglesa ocorreu na escola de ensino regular. $O$ fato de $o$ adolescente ter sua língua materna como a única língua com a qual já teve contato pode predispor o surgimento de paixões não favoráveis ao aprendizado em relação a esta segunda língua.

A psicanálise considera a língua materna "fundante da subjetividade, língua do prazer e do repouso" (CORACINI, 2007, p. 152), portanto ser inserido em uma nova língua, uma língua estranha àquele sujeito, a língua do outro significaria sair da zona de conforto em que ele se encontra para experimentar o novo, e num primeiro momento esse novo pode provocar sentimentos dos mais variados. Acrescido a isso, justamente por não manifestarem nenhum contato prévio com a língua, esses adolescentes também não estão seguros sobre a aplicabilidade desse idioma em suas vidas no futuro, portanto hipotetizam um uso futuro para esta segunda língua. Esse aspecto está expresso em um dos relatos que escolhemos: 
"O inglês pra mim é muito importante porque se eu precisar de fazer um curso algum dia o inglês irá me ajudar."

O uso da conjunção condicional "se" atribui um sentido hipotético para a frase do estudante. Expressando não visualizar um uso efetivo para a língua inglesa no momento, o aprendiz declara um possível uso para essa língua futuramente, apesar de essa aplicabilidade futura do idioma não passar apenas de uma hipótese, ou seja, esse uso pode ocorrer ou não.

Essas hipóteses que os adolescentes da escola de ensino regular fazem sobre o uso efetivo da língua inglesa em suas vidas evidenciam certa distância entre os discentes e o idioma. Como se trata de uma língua não inserida em suas realidades, os estudantes projetam uma prática distante para o que estão aprendendo no momento atual, como mostra o trecho a seguir:

"Daqui alguns anos o inglês será muito importante para meu futuro porque um dia eu precisarei do inglês."

As expressões temporais utilizadas pelo aluno, "daqui alguns anos" e "um dia", e ainda os verbos no futuro, "será" e "precisarei", excluem a língua inglesa do contexto social do aluno, comprovando assim a distância entre ele e o idioma.

Essa distância entre os aprendizes e a segunda língua e o uso hipotético que esses adolescentes atribuem ao idioma pode ser resultado da ausência de modelos na realidade de vida do estudante. Não existindo modelos em seu contexto social, o adolescente, na maioria das vezes, encontra somente a figura do professor de língua inglesa como sua única forma de contato com o idioma. O professor atua, frequentemente, como o único meio do aprendiz para ter acesso à língua. Essa ligação que o professor possibilita entre o estudante e a língua é atestada pela seguinte declaração de um dos alunos da escola de ensino regular:

"O inglês é tão legal quanto a professora Sinelle."

A partir desse relato percebemos que a língua inglesa apenas tem um sentido positivo na vida desse adolescente porque ele 
primeiramente se identifica com a professora. Sendo essa professora encarregada de transmitir-lhe esse novo idioma, esse aluno demonstra uma predisposição em aprendê-lo, não devido ao idioma, mas devido à figura que o conduz ao idioma.

Todos esses aspectos apresentados que caracterizam os aprendizes da escola de ensino regular impulsionam uma propensão a uma desidentificação inicial desses adolescentes com a língua inglesa, e isso explica o fato de algumas paixões que afastavam os estudantes do idioma terem sido percebidas justamente nos primeiros contatos desses aprendizes com a língua.

$\mathrm{Na}$ sequência, passamos para a investigação dos textos redigidos por aprendizes da escola de idiomas, o que nos permitirá uma comparação entre esses dois ambientes de ensino da língua inglesa.

\section{As paixões na escola de idiomas: a construção de um perfil}

Nesta seção será possível não apenas apresentarmos as paixões manifestadas nos textos dos aprendizes da escola de idiomas e caracterizarmos essa instituição, mas também nos dedicaremos a confrontar essas duas realidades de ensino da língua inglesa: a escola de ensino regular e a escola de idiomas.

Voltando nossa atenção para as paixões afloradas nos aprendizes da escola de idiomas, constatamos que o amor, que foi uma paixão comum a todos os integrantes investigados da escola de ensino regular, também foi unânime a todos os alunos da escola de idiomas. Exemplificamos a seguir, por intermédio de alguns excertos das redações, como esse sentimento foi evidenciado nessa realidade de ensino.

\section{"Eu adoro inglês."}

"Eu amo inglês."

"Tomei gosto por ouvir, entender e aprender inglês."

Essas frases redigidas pelos adolescentes em relação à língua inglesa em suas vidas nos fazem perceber que esses aprendizes conseguiram identificar-se com essa nova língua, portanto podemos 
concluir que o amor foi suscitado, uma vez que, segundo Meyer (2003, p. XLIV), o amor é "certamente um vínculo de identidade".

No entanto, diferentemente do que ocorreu na escola de ensino regular, na qual uma única paixão se sobressaiu em relação às demais, na escola de idiomas, concomitantemente ao amor, outra paixão foi manifestada com a mesma intensidade - a emulação.

No trecho a seguir, escrito por um dos aprendizes da escola de idiomas, podemos observar uma das características da emulação sendo destacada:

"Quando ouvia músicas, assistia filmes etc., ficava interessado em saber o que dizia. Procurei uma vez na internet uma letra e gostei... assim continuei ouvindo e vendo a letra, isso fez com que melhorasse minha pronûncia."

Sendo a emulação conceituada por Aristóteles (2007, p. 108) como "um sentimento bom percebido por pessoas boas" e que quando somos afetados por ela essa paixão "faz com que tomemos as medidas necessárias para garantir essas coisas boas", podemos associar, neste estudo, "essas coisas boas" ao domínio da língua inglesa e "as medidas necessárias para garantir essas coisas boas" ao fato de o estudante recorrer à internet para satisfazer seu desejo.

$\mathrm{O}$ adolescente emulado procura um meio para alcançar o que deseja, e somente apresenta tal desejo porque visualiza modelos que o levam a querer imitá-los, igualar-se a eles ou aproximar-se deles e, nessa situação, as músicas e os filmes na língua alvo funcionaram como modelos para que o estudante fosse motivado a buscar a língua.

Neste outro excerto das redações provenientes da escola de idiomas, outra paixão pode ser percebida - a confiança -, que também foi manifestada na escola de ensino regular.

\footnotetext{
"Você se sente muito mais 'alfabetizado', incluso naquele grupo."
}

Por intermédio dessa declaração esse estudante expressa que, no mundo atual, o fato de não dominar uma segunda língua poderia deixá-lo marginalizado de um grupo já detentor daquele saber e, 
provavelmente, este seria um grupo no qual o aprendiz desejaria estar inserido.

Assim como Meyer (2003, p. XLV) afirma que a confiança "provém de uma certa superioridade tanto sobre as coisas quanto sobre as pessoas", o conhecimento da língua inglesa proporciona essa superioridade ao adolescente, permitindo sua inclusão em um grupo diferenciado - o dos falantes desse novo idioma.

Apresentamos agora um trecho de uma redação em que, no início, o aluno se mostrava preocupado e inquieto por não saber nada sobre esta segunda língua. Porém, ao final de seu texto, temos a impressão de que a situação conflitante foi superada.

\section{"Tudo ficou mais claro, palavras, frases, textos."}

Neste momento da aprendizagem podemos afirmar que a calma foi manifestada nas palavras desse aluno, pois ela "é a aceitação de uma relação" (MEYER, 2003, p. XLIV). Quando o aprendizado começou a concretizar-se, o adolescente começou a aceitar essa nova língua.

Uma última paixão a ser percebida em apenas um dos textos analisados pertencentes à escola de idiomas foi a indignação. Contudo, o estudante menciona que esse sentimento o acometeu quando ele ainda mantinha contato com a língua inglesa apenas na escola de ensino regular. Logo, a solução encontrada por esse adolescente para reverter a paixão que o afastava dessa segunda língua foi matricular-se em uma escola de idiomas.

"A língua oficial do mundo, todo mundo sabia um pouco e eu não. Primeira série na escola foi o primeiro contato que eu tive com esta língua tão rica e bonita."

Para Meyer (2003, p. XLVI), “a indignação reflete a não aceitação (moral) do espetáculo das paixões, de sua desordem”. Dessa forma, estamos diante de um aprendiz que não aceitava que outros sujeitos possuíssem um conhecimento que ele sequer havia tido contato anteriormente. No entanto, embora essa paixão tenha sido despertada em um dos estudantes da escola de idiomas, precisamos considerar, como já foi explicado, que ela se manifestou no momento 
em que seu contato com a língua se restringia ao ambiente da escola de ensino regular.

Após a apresentação de alguns excertos das redações oriundas da escola de idiomas, podemos elencar as paixões manifestadas pelos aprendizes dessa instituição: o amor, a emulação, a confiança, a calma e a indignação. A incidência de cada um desses sentimentos pode ser conferida na Figura 2:

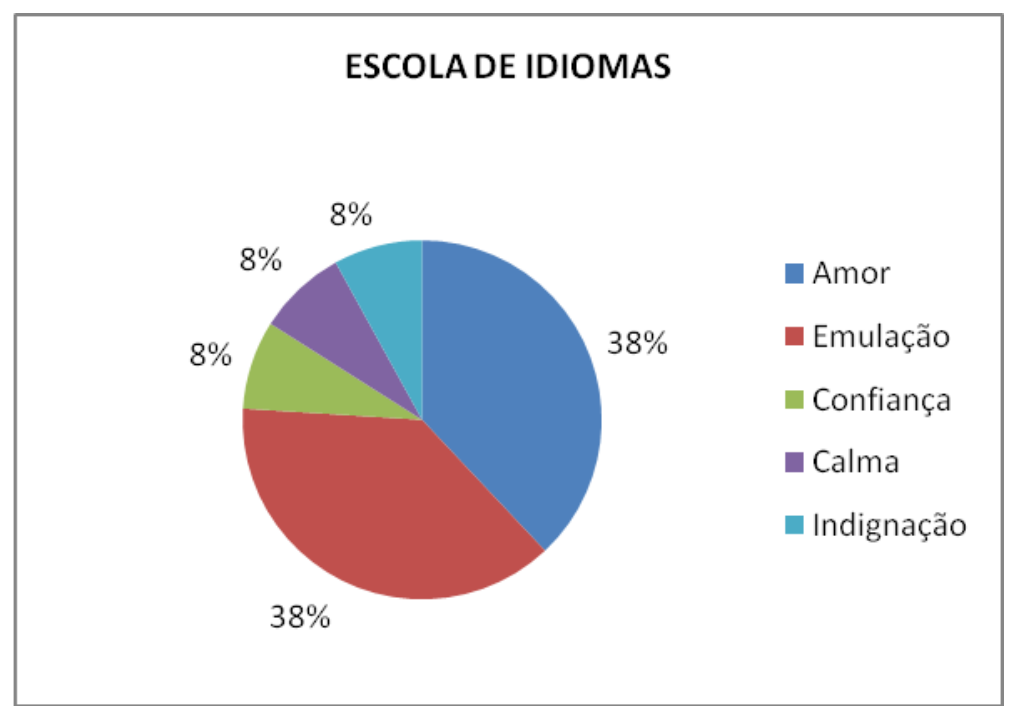

Figura 2. As paixões manifestadas em textos de alunos da escola de idiomas

Assim como fizemos com a escola de ensino regular, também destacaremos alguns fatores percebidos na escola de idiomas que além de caracterizarem esse ambiente de ensino também favorecem que algumas paixões e sua incidência sejam divergentes entre as duas realidades investigadas.

Uma primeira característica a ser apreendida por meio dos relatos dos aprendizes com base em seus textos e que distingue completamente esses dois tipos de público é que, de forma oposta ao que ocorre na escola de ensino regular, na escola de idiomas todos os estudantes expressaram ter tido algum contato prévio com a língua alvo anterior ao seu ingresso na instituição de ensino. 
Enquanto aos alunos da escola de ensino regular a língua inglesa se apresentava como uma língua "estranha" a eles, uma vez que ignoravam até mesmo a terminologia "língua inglesa", aos discentes da escola de idiomas esta segunda língua parece estar inserida em suas vidas há algum tempo, até mesmo de forma inconsciente, assim como é relatado por um aprendiz pertencente à escola de idiomas:

"Desde de criança já cantava em inglês, na verdade uma musica da banda Red Hot Chilli Peppers (música Californication) nem sabia que era inglês, apenas cantava porque achava legal."

Esse estudante declara que a língua inglesa já fazia parte de sua infância sem ele nem ao menos ter conhecimento que se tratava desse idioma específico, ou seja, seus primeiros contatos com a língua ocorreram de maneira informal, fora do ambiente escolar.

$\mathrm{O}$ tratamento da língua inglesa como um acontecimento natural na vida desses aprendizes da escola de idiomas pode ser evidenciado por meio de outro aspecto que também diferencia esses dois universos de aprendizagem. Os adolescentes que mantêm contato com a língua alvo nesta instituição visualizam um uso futuro do idioma de maneira consciente, diferentemente do outro público investigado, que apenas levantava hipóteses sobre um possível uso do idioma em algum momento no futuro, mas não chegava nem a mencionar alguma forma real de atuação dessa língua em sua vida.

Os alunos da escola de idiomas demonstram, por meio de suas previsões em relação à aplicabilidade do inglês em suas vidas, que realmente têm certeza que o idioma estará presente em suas vidas no futuro. E eles exemplificam essa assertiva mencionando suas ações futuras nas quais o idioma estará envolvido, assim como podemos perceber pelo excerto a seguir de um dos textos desses aprendizes:

\section{"Pretendo continuar e finalizar o meu curso para que um dia} eu possa fazer um intercambio."

Nesse relato, este estudante exprime seu desejo de fazer um intercâmbio, e para que essa vontade se concretize, o aprendizado da 
língua que ele está tendo no momento e que prosseguirá no futuro será essencial.

A partir desse excerto do texto redigido pelo estudante da escola de idiomas, é importante destacar o tipo de público atendido por essa instituição de ensino, que é um dos fatores que a diferencia de uma escola pública. Como a escola de idiomas é uma instituição privada, estima-se que seus estudantes detêm um poder aquisitivo superior ao dos estudantes de uma escola pública, e esse fato permite que esses discentes possam considerar a possibilidade de utilizar essa segunda língua que estão aprendendo em uma situação real.

Em outro texto, um adolescente menciona uma viagem iminente ao exterior, o que também demonstra uma aplicabilidade segura para o idioma. Assim como mencionado no parágrafo anterior, essas pretensões apenas podem ser premeditadas de forma real devido à condição financeira do aprendiz lhe permitir tais desejos. Ademais da condição financeira, o meio social no qual o aluno está inserido também o influencia a expressar tais anseios, pois questões como estas provavelmente fazem parte de sua realidade. Dessa forma, os públicos distintos que cada uma dessas instituições atende também concorrem para que determinadas diferenças sejam expressas entre essas duas realidades.

A língua inglesa também é considerada pelos discentes da escola de idiomas devido a sua contribuição em suas vidas profissionais. Esses adolescentes mostram, por meio de seus textos, estar conscientes da importância do domínio de uma segunda língua independentemente da carreira que venham a seguir. Isso possibilita que os planos dos estudantes da escola de idiomas em relação à língua inglesa sejam traçados de forma segura, e não apenas como hipóteses, como acontecia com o outro público analisado, é que, para esses aprendizes, a língua inglesa está inserida em seu contexto social, ela acompanha o aluno em seu próprio ambiente familiar.

Os adolescentes da escola de idiomas mencionam ter modelos ao seu redor, presentes no seu convívio diário para poder seguir, de forma contrária ao que acontecia com os estudantes da escola de ensino regular, que careciam de qualquer modelo para estimular seu aprendizado. Entre os modelos relatados por esses aprendizes está a figura do irmão mais velho que já domina o idioma, e esse fato faz com que, admirando o irmão, este adolescente queira igualar-se a ele. 
Além disso, o acesso à internet também estimula a vontade do aluno de aprender a língua alvo, uma vez que, no desejo de contactar pessoas que falam o idioma, ele busca interagir por meio desse idioma. E ainda as bandas internacionais cujas músicas o aprendiz goste de escutar também atuam como motivadoras do aprendizado.

No trecho transcrito a seguir proveniente de uma das redações originadas na escola de idiomas, o aprendiz evidencia a figura de seu irmão mais velho como um modelo para ele, e ainda expõe o papel relevante que o irmão teve na construção de seu aprendizado.

"Eu já sabia um pouco de inglês porque meu irmão mais velho já me ensinava."

Enquanto todos os alunos da escola de idiomas exibiam modelos que os conduziam ou lhes inspiravam o aprendizado, os estudantes da escola de ensino regular relatavam a existência apenas da figura do professor de língua inglesa para aproximá-los da língua alvo.

Se na escola de ensino regular a relação entre o adolescente e a língua inglesa é mediada pela figura do professor, na escola de idiomas essa relação é mediada pela realidade, parece-nos que o próprio contexto social em que o aluno está inserido requer dele esse conhecimento.

Dessa forma, uma vez que as características percebidas nos relatos dos discentes da escola de ensino regular nos levavam a uma desidentificação inicial com a língua alvo, de modo inverso, os aspectos observados nos textos dos estudantes da escola de idiomas revelam uma propensão à identificação com a língua estrangeira desde o início.

A próxima parte deste estudo é reservada a fazer um paralelo entre essas duas realidades de ensino da língua inglesa que foram investigadas nesta pesquisa por meio do confronto das paixões percebidas em cada instituição. 


\section{A língua inglesa em dois universos distintos}

Nesta última seção dedicamo-nos a confrontar as paixões manifestadas nos relatos dos estudantes de língua inglesa pertencentes à escola de ensino regular e à escola de idiomas.

Apresentamos inicialmente a Tabela 1, que evidencia a incidência das paixões apreendidas em cada uma das instituições analisadas de acordo com os sentimentos que cada aprendiz exteriorizou em seu texto. Separamos as paixões de acordo com as redações advindas das escolas em que elas foram concebidas. A fim de preservar a identidade dos adolescentes autores das redações, utilizamos siglas para identificá-los. Os alunos que redigiram seus textos e pertencem à escola de ensino regular foram denominados de $\mathrm{R} 1$ a R5, e os demais alunos, oriundos da escola de idiomas, foram identificados como I1 a I5.

A Tabela 1 evidencia que algumas paixões não foram percebidas em nenhuma das redações, ao passo que outros sentimentos apareceram em todos os textos ou em quase todos. Outras paixões, no entanto, foram comuns apenas a uma das instituições de ensino analisadas. A cólera, o temor, o ódio, a vergonha, a impudência, o favor, a compaixão e a inveja são sentimentos que não foram manifestados em nenhum momento por nenhum dos aprendizes em seus textos. As demais paixões foram suscitadas em pelo menos um dos alunos que fazem parte das amostras desta pesquisa.

É interessante ressaltar que enquanto a emulação foi suscitada em todos os aprendizes da escola de idiomas, assim como está destacado na cor verde na tabela, na escola de ensino regular houve casos em que esta paixão não foi manifestada, estando essa ausência marcada pela cor azul. No entanto, nos textos em que este sentimento esteve ausente, outra paixão foi despertada: o desprezo, que também está destacado na cor verde para evidenciar a sobreposição deste sentimento em relação à emulação. 
Tabela 1. Comparação das paixões

na escola de ensino regular e na escola de idiomas

\section{Escola}

de ensino regular

\section{Escola de idiomas}

\begin{tabular}{lllllllllll} 
Paixões & R1 & R2 & R3 & R4 & R5 & I1 & I2 & I3 & I4 & I5 \\
\hline
\end{tabular}

Cólera

Calma X $\quad$ X

Temor

Confiança

Amor

\begin{tabular}{|lllllllllll|}
$\mathbf{X}$ & $\mathbf{X}$ & & & & & $\mathbf{X}$ & & & & \\
\hline $\mathbf{X}$ & $\mathbf{X}$ & $\mathbf{X}$ & $\mathbf{X}$ & $\mathbf{X}$ & & $\mathbf{X}$ & $\mathbf{X}$ & $\mathbf{X}$ & $\mathbf{X}$ & $\mathbf{X}$ \\
\hline
\end{tabular}

Ódio

Vergonha

Impudência

Favor

Compaixão

Indignação

$\mathbf{X}$

Inveja

Emulação

Desprezo

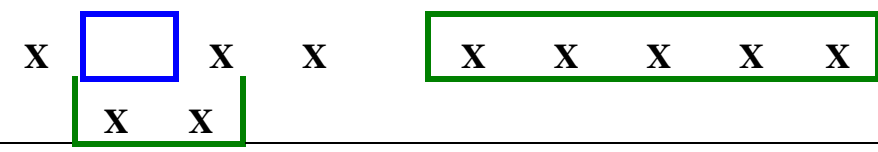

Sendo a emulação o desejo de igualar-se ao outro, na ausência de um modelo surge o desprezo, isto é, despreza-se o outro. Segundo Aristóteles (2003, p. 7), esse outro "não parece digno de consideração", uma vez que não reconheço sua importância. E as únicas manifestações do desprezo nos textos dos discentes analisados foram justamente nos dois casos em que a emulação não foi despertada, como foi identificado na tabela pelas cores azul e verde.

Ainda na tabela, na cor vermelha destacamos uma paixão comum às duas realidades de ensino da língua inglesa: o amor. Essa paixão foi manifestada por todos os aprendizes do idioma, sem exceção. De acordo com Meyer (2003, p. XLIV), "o amor, ou a amizade é certamente um vínculo de identidade. É o próprio lugar da conjunção, da associação", podemos assim concluir que houve a 
identificação de todos os aprendizes com a língua inglesa, mesmo que essa identificação não tenha sido evidenciada desde os momentos iniciais de contato do adolescente com a língua nas duas realidades.

\section{Conclusão}

Em nossa sociedade foi disseminada a ideia de que em uma escola de ensino regular, especialmente na escola pública, é impossível se aprender uma língua estrangeira. Essa crença é fundamentada nas várias peculiaridades que divergem essa instituição de ensino de uma escola de idiomas, sendo esta última considerada por muitos o ambiente propício a esse aprendizado.

As características que concorrem para esse ponto de vista a respeito das escolas que se dedicam exclusivamente ao ensino da língua inglesa vão desde aspectos que levam em conta a estrutura física dos dois ambientes de ensino, bem como as relações interpessoais que particularizam cada uma dessas instituições. Amplo espaço físico, que permite acomodar confortavelmente seus alunos, limitando o número destes em cada turma, uso da tecnologia, dispondo de diversos recursos audiovisuais que auxiliam na apresentação da nova língua ao aluno, e a contínua capacitação do corpo docente são apenas alguns dos fatores que concorrem para que a escola de idiomas seja considerada um ambiente privilegiado para o aprendizado efetivo da língua inglesa.

No entanto, apesar de a escola de ensino regular e a escola de idiomas serem consideradas ambientes distintos em relação ao ensino de uma língua estrangeira, ambas conseguiram despertar paixões que levaram seus aprendizes à identificação com a língua inglesa.

Tratando-se de duas realidades distintas de aprendizado de uma língua estrangeira, as características particulares de cada ambiente de ensino demandam, pelo professor, o uso de estratégias argumentativas diversificadas para seduzir e convencer seu auditório.

A escola de ensino regular, na ausência de modelos na realidade do aprendiz, requer que o professor de língua estrangeira busque modelos mais palpáveis para a inserção desse adolescente na língua alvo, de modo que a língua inglesa saia do modo hipotético e passe a ter uma aplicabilidade real na vida do estudante. 
Sabendo-se que o tipo de argumentação do professor revela o universo no qual o aprendiz está inserido, cabe ao professor de língua estrangeira tentar amenizar as diferenças iniciais percebidas em cada instituição, fazendo com que a relação entre o estudante e a língua estrangeira seja mediada pela realidade, para que assim a identificação entre o adolescente e a língua seja percebida desde os primeiros contatos.

\section{Referências}

ARAGÃO, Rodrigo C. A dimensão afetiva na instrução formal. In: MAGALHÃES, José ; TRAVAGLIA, Luis Carlos. (Org.). Múltiplas perspectivas em lingüística. Uberlândia: Edufu, 2008.

ARISTÓTELES. Ética a Nicômaco. Tradução de António de Castro Caeiro. São Paulo: Atlas, 2009.

Retórica. Tradução de Marcelo Silvano Madeira. São Paulo: Rideel, 2007 (Coleção Biblioteca Clássica).

Retórica das paixões. Prefácio de Michel Meyer. Introdução,

notas e tradução do grego: Isis Borges B. da Fonseca. São Paulo: Martins Fontes, 2003.

CORACINI, Maria J. A celebração do outro. Campinas: Mercado de Letras, 2007.

DUARTE, Stênio F. P.; SOARES, Fabyano G.; RODRIGUES, Adriana L. Guia para composição de projeto de pesquisa. 2011. Disponível em: <http://www. http://ebookbrowse.com/fainor-guiapara-composição-de-projeto-de-pesquisa-pdf-d87486744>. Acesso em: $10 / 11 / 2012$.

HOUAISS, Dicionário eletrônico. CD (2001).

HUME, David. Tratado da natureza humana. Tradução de Serafim da Silva Fontes. Lisboa: Fundação Calouste Gulbenkian, 2001. 
LAPLANCHE, Jean; PONTALIS, Jean-Bertrand. Vocabulário da psicanálise. Tradução de Pedro Tamen. 4. ed. São Paulo: Martins Fontes, 2001.

LIGHTBOWN, Patsy M.; SPADA, Nina. How languages are learned. New York: Oxford University Press, 2006.

MASTRELLA-DE-ANDRADE, Mariana R. (Org.). Afetividade $e$ emoções no ensino/aprendizagem de línguas: múltiplos olhares. Campinas: Pontes Editores, 2011.

MATURANA, Humberto. Emoções e linguagem na educação e na política. Tradução de José Fernando Campos Fortes. Belo Horizonte: UFMG, 1998.

MEYER, Michel. A retórica. Tradução de Marly N. Peres. São Paulo: Ática, 2007.

ZIMERMAN, David E. Vocabulário contemporâneo de psicanálise. Porto Alegre: Artmed, 2001.

Submetido em: 17/08/2013 Aceito em: 13/10/2014

Title: The Aristotelian passions in the characterization of two universes: English at the language school and at the regular school 